\title{
Thermal Vapor Ablation for Lung Lesions in a Porcine Model
}

\author{
Erik Henne $^{\mathrm{a}}$ J. Scott Ferguson ${ }^{\mathrm{b}}$ Robert Mest ${ }^{\mathrm{a}}$ Felix J.F. Herth ${ }^{\mathrm{c}}$ \\ ${ }^{a}$ Research and Development, Uptake Medical, Tustin, Calif., and ${ }^{b}$ Department of Medicine, University of Wisconsin \\ School of Medicine and Public Health, Madison, Wis., USA; ${ }^{\circ}$ Department of Pneumology and Respiratory Critical \\ Care Medicine, Thoraxklinik, University of Heidelberg, Heidelberg, Germany
}

\section{Key Words}

Tumor, lung · Lung cancer surgery · Ablative therapy ·

Bronchoscopy $\cdot$ Bronchus

\begin{abstract}
Background: Various methods for ablating peripheral lung lesions are being investigated; however, none have been successfully adapted for delivery via bronchoscopy. Vapor ablation is currently being used to bronchoscopically create lung volume reduction in emphysema patients. Objectives: In this study, an adaptation of that technology is evaluated for potential treatment of lung lesions in a live pig model. Methods: In 5 anesthetized healthy pigs, vapor of varying energy levels was delivered bronchoscopically to 66 different lung subsegments with airway diameters of 2-5 $\mathrm{mm}$. Two hours after treatment, a necropsy was performed and the ablated regions were assessed for ablation and tissue structure disruption. In 6 additional pigs, vapor was applied to 3 subsegments each. To evaluate the progression of the response to treatment, 2 were kept alive for 10 days, 2 for 21 days, and 2 for 32 days. Results: Histopathological evaluation of the sections demonstrated that vapor is capable of creating a uniform field of necrosis following the subsegment anatomical boundary. The reliability of a uniform field is dependent on the level of energy delivered. An energy
\end{abstract}

level that reliably creates a uniform field of necrosis was applied in chronic animals. The animals tolerated the procedure and posttreatment care. No cardiac arrhythmias, hemorrhage, stroke, respiratory distress, or pneumothorax occurred during or after treatment. Conclusions: Vapor ablation is a potentially safe and efficient means of ablating a targeted region of the lung. We hypothesize that vapor may be useful in treating lesions of the lung in humans.

(c) 2015 S. Karger AG, Base

\section{Introduction}

Surgery is currently the treatment of choice for patients with early-stage non-small cell lung cancer (NSCLC), which can often be cured through resection alone. However, many of these patients have significant comorbidities and therefore have a significant risk of morbidity and mortality and a resultant high resource utilization [1]. Thirty-eight percent of patients undergoing resection experience major complications and a loss of exercise capacity. Complications and the risk of mortality and morbidity increase in older patients and patients with other significant medical conditions [2]. As the treatment for lung cancer has evolved, alternatives to surgical resection have been considered as a possible means of avoiding major

\begin{tabular}{ll}
\hline KARGER 125.3 & $\begin{array}{l}\text { (2) 2015 S. Karger AG, Basel } \\
0025-7931 / 15 / 0902-0146 \$ 39.50 / 0 \quad \text { Karger }\end{array}$ \\
$\begin{array}{l}\text { E-Mail karger@karger.com } \\
\text { www.karger.com/res }\end{array}$ & $\begin{array}{l}\text { This is an Open Access article licensed under the terms of the } \\
\text { Creative Commons Attribution-NonCommercial 3.0 Un- } \\
\text { ported license (CC BY-NC) (www.karger.com/OA-license), } \\
\text { applicable to the online version of the article only. Distribu- } \\
\text { tion permitted for non-commercial purposes only. }\end{array}$
\end{tabular}

Erik Henne, BSME

1173 Warner Ave

Tustin, CA 92780 (USA)

E-Mail ehenne@ uptakemedical.com 
Fig. 1. Schematic of thermal vapor ablation

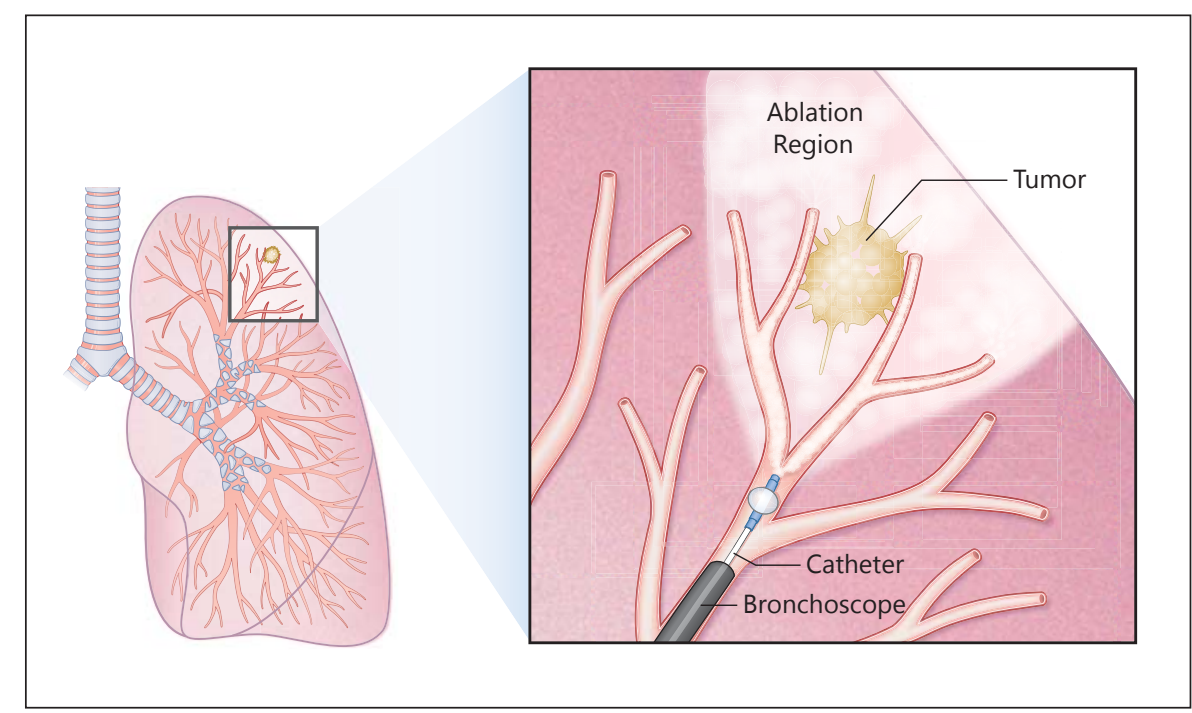
for lung lesions.

complications. Additionally, many patients have multiple cancers in the lung, either from independent primaries or from metastatic lesions that may benefit from local intervention [3] but become less amenable to resection when multiple lobes are involved.

CT-guided percutaneous ablation techniques in the form of radiofrequency, microwave, or cryotherapy have recently been developed as alternative methods for treating these tumors in nonoperable patients [4]. While ablation is proven to be capable of controlling tumors, pneumothorax, bleeding, and bronchopleural fistula continue to be problematic risks of these percutaneous procedures [5-7]. Avoidance of a percutaneous approach will greatly reduce the rate of complications due to these ablative technologies. To date, none of these techniques has been successfully adapted for bronchoscopic application, which would avoid percutaneous complications. Stereotactic body radiation therapy has also been adapted for pulmonary tumors. The treatment, however, has significant toxicity risks [8], requires multiple sessions, and is limited to centers that can afford the capital expenditure. A bronchoscopic approach to treating these lesions has the potential to improve mortality and morbidity, lessen breathing impairment, lower costs, and improve the quality of life as compared to resection [9]. A bronchoscopic technique could feasibly be used to treat early-stage lung cancer in the same procedure as diagnosis and staging, further reducing the treatment impact on the patient [9].

Vapor ablation has been successfully used for bronchoscopic lung volume reduction in patients with emphysema $[10,11]$. The technology has been adapted with the intent of using vapor energy to ablate lung regions containing lesions. It is thought that infusing vapor into a small lung subsegment could generate a uniform field of necrosis in the parenchyma along the natural anatomical boundaries of that subsegment. A schematic of this is presented in figure 1 . This field of necrosis would result in ablation of the lesion and the surrounding parenchymal margin. With vapor ablation for lung lesions, the intent is to create a uniform field of necrosis around the lesion. By ablating the supporting vasculature, lymphatics, and other tissue around the lesion, the portions of the lesion that have not been directly ablated proceed to necrosis due to ischemia. Because treatment of the lesion occurs from the outside in, there are fewer concerns about complete ablation of the margin, which is an issue with other techniques [12]. Like vapor ablation for emphyse$\mathrm{ma}$, the system consists of a reusable vapor generator with a disposable vapor catheter used to deliver heated water vapor through a bronchoscope to the targeted lung subsegment.

The objective of the current study was to evaluate the potential efficiency and safety of thermal vapor ablation for lung lesions in a live animal model across a wide energy range. Healthy pigs were chosen as the model because of the many anatomical similarities with the human lung (size, density, and airway branching pattern). Because the mechanism of action is to ablate the parenchyma around a lesion, healthy pigs without lesions are a suitable model to evaluate the effect of vapor in the lung. Normal pig lungs have been used to investigate ablation in the lung with other modalities [13-17]. 
Table 1. Treatment summary

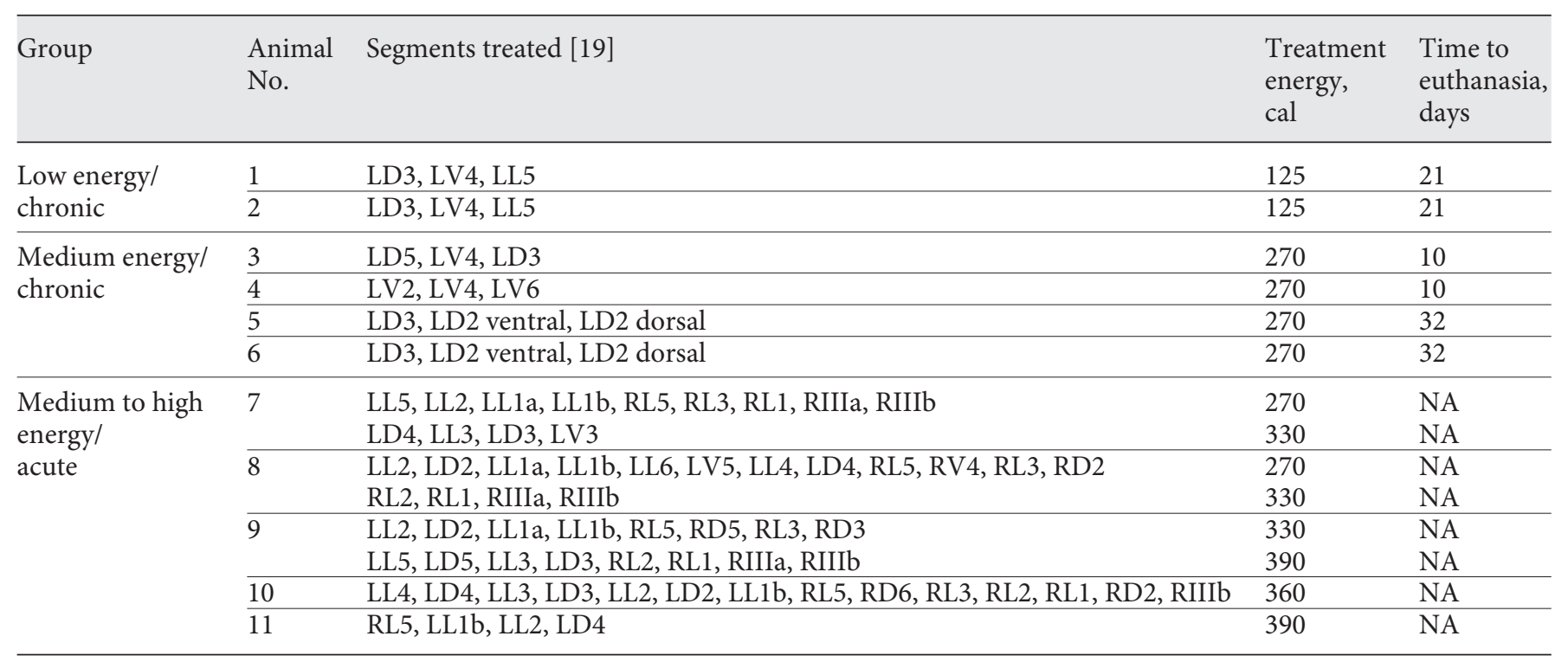

NA $=$ Not applicable

\section{Materials and Methods}

All procedures were reviewed and approved by the Institutional Animal Care and Use Committee of American Preclinical Services (Coon Rapids, Minn., USA). All experimentation and husbandry occurred at American Preclinical Services according to their standard operating procedures. The energy output of the vapor system was measured via water bath calorimetry.

The methods and results of the technique reported in this paper are part of a larger development experiment for adaptation of vapor ablation for lung lesions that included other application techniques, such as use of a needle-tipped catheter. For efficiency, multiple techniques were evaluated per animal. The results of these other techniques will be reported in other publications.

\section{Treatment Procedures}

Eleven Yorkshire pigs were used in this study, including $3 \mathrm{fe}-$ males and 8 castrated males. The average age at the time of treatment was 4.4 months (range 3.1-6.6) and the average weight was $56.6 \mathrm{~kg}$ (range 46.4-67). Prior to treatment, measurements of vital signs were taken and blood work was done for clinical pathology analysis.

Vapor ablation was delivered to the lungs of the anesthetized and intubated animals via a vapor catheter connected to a vapor generator in a manner similar to the emphysema approach [10]. However, smaller subsegments were targeted with the intent of delivering a higher energy density to completely perfuse the parenchyma airspace with vapor (which is not the intent of the emphysema approach) [18]. Because the intent was to completely perfuse subsegments of a similar size, fixed energy levels rather than mass scaled energy doses were evaluated. The catheter was navigated to each target airway with a $2.0-\mathrm{mm}$ working channel bronchoscope. Airways were labeled according to the morphology described by
Nakakuki [19]. Airways in the range of $2-4 \mathrm{~mm}$ in diameter were selected for treatment. An occlusion balloon was inflated in the airway and vapor was delivered at a specific energy level. Total energy in the range of 125-390 cal per treatment was delivered at a constant flow rate for $8 \mathrm{~s}$ without repetition and with the ventilator turned off.

Treatment of the two 32-day chronic animals consisted of vapor delivery to adjacent subsegments because clinical application may require multiple adjacent treatments. Treatment of the other chronic and acute animals was done in nonadjacent subsegments to better discern individual effects. Table 1 summarizes the treatments and energy delivered to each animal.

Each animal was anesthetized, intubated, and mechanically ventilated. For each treatment, the catheter was placed in the airway under visual guidance with the bronchoscope and the balloon was inflated to seal the airway. During the treatment period, vitals (oxygen saturation and heart rate) were continuously monitored. Any complications that occurred during treatment were documented.

\section{After the Procedure}

The acute-treatment animals were kept under anesthesia for $2 \mathrm{~h}$ after the last treatment before being euthanized and subjected to a necropsy. The chronic animals were recovered from anesthesia and returned to their housing. Clinical observations were performed daily by animal facility staff for the duration of the survival period.

Trained staff performed a limited necropsy evaluation of organs and tissue, and abnormal findings were noted. Cross-sectional slices of each treated segment were made, and they were inspected for uniform necrosis and for the presence of pneumatoceles. Representative sections were stained with hematoxylin and eosin (H\&E) and processed for histopathology slides. 


\section{Results}

A total of 84 treatments (66 acute and 18 chronic) were delivered via the vapor application technique described in this report. The energy and location for each individual treatment are shown in table 1. Animals 1-4 and 11 also had vapor applications with other techniques in other lobes not reported in this study. Vapor applications of different techniques were never applied in the same lobe; therefore, the evaluation of the local effects was not affected by the additional treatments. However, in the chronic animals, it was not possible to clearly identify whether a clinical observation was due to one treatment technique or another. Therefore, all clinical observations are reported.

\section{General Observations}

All treatments were delivered as intended, except for 3 which had occlusion balloon deflation or premature cessation. These were considered failed deliveries and not included in the analysis.

An immediate observed effect of the treatment was blanching of the airway after vapor delivery. Treatments were generally well tolerated, except in some of the acute animals, which had a high number of treatments and high energy levels. Procedural complications were present in 3 of the 5 acute animals. Animal 9, treated with mediumhigh energy 16 times, did not survive the postoperative 2-hour holding period. Upon necropsy, this animal was found to have evidence of a bilateral pneumothorax. Animals 10 and 11 also had complications during the procedure related to pneumothorax. Both of these animals had at least 10 treatments in total, including treatments with other vapor methods.

The procedure was well tolerated in the chronic cohort of animals $(n=6)$ and all survived to the scheduled termination date. No clinical observations consistent with embolism, infarct, pneumonia, hemorrhage, respiratory failure, or pneumothorax were noted.

At the time of termination, 2 animals had clinical pathology findings characteristic of a systemic inflammatory response. One of these animals (No. 2) also exhibited an elevated temperature and a loss of appetite. The other animal (No. 5) also exhibited a loss of appetite and had evidence of pericardial effusion upon necropsy.

\section{Gross Pathology}

Disruption of the lung architecture (referred to as pneumatoceles) was a common observation upon inspection of the treated regions of the lung. The pneumatoceles were sometimes entirely within the parenchyma and
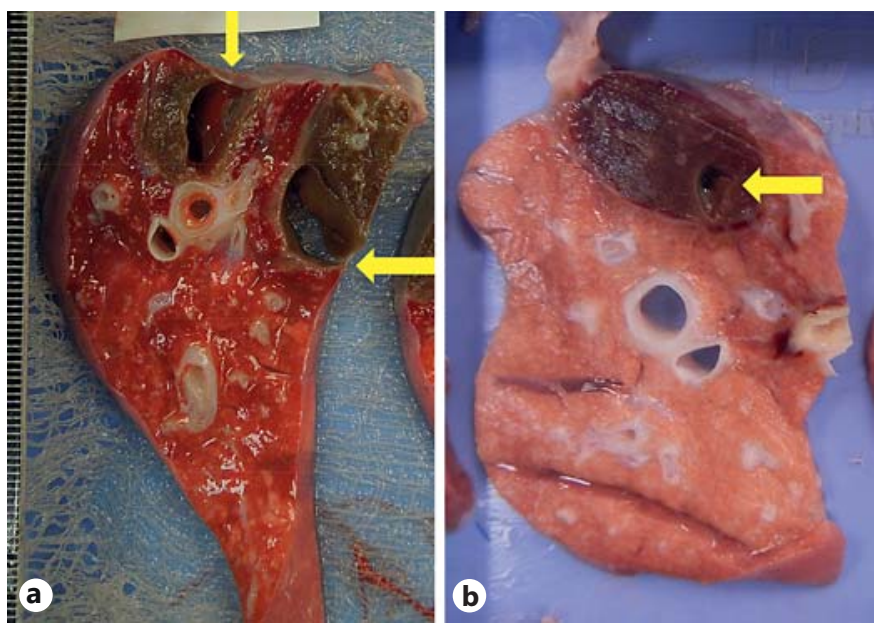

Fig. 2. Representative images of pneumatoceles (arrows). a Pneumatocele involving the pleural surface of segment LV3 after acute treatment with $330 \mathrm{cal}$ (animal 7). b Pneumatocele without involvement of the pleural surface of segment LD3 ten days after treatment with $270 \mathrm{cal}$ (animal 3).

Table 2. Frequency of pneumotoceles in the treated segments by treatment energy

\begin{tabular}{llll}
\hline $\begin{array}{l}\text { Treatment } \\
\text { energy }\end{array}$ & $\begin{array}{l}\text { Treatments, } \\
\mathrm{n}\end{array}$ & $\begin{array}{l}\text { Pneumatoceles } \\
\text { observed, n (\%) }\end{array}$ & $\begin{array}{l}\text { Surface } \\
\text { pneumatoceles } \\
\text { observed, n (\%) }\end{array}$ \\
\hline $125 \mathrm{cal}$ & 6 & $0(0)$ & $0(0)$ \\
$270 \mathrm{cal}$ & 33 & $8(24)$ & $2(6)$ \\
$330 \mathrm{cal}$ & 16 & $11(69)$ & $11(69)$ \\
$360 \mathrm{cal}$ & 14 & $11(79)$ & $10(71)$ \\
$390 \mathrm{cal}$ & 12 & $4(33)$ & $2(17)$ \\
\hline
\end{tabular}

sometimes extended to the pleural surface, but without disrupting it. Representative images of pneumatoceles are provided in figure 2 . The frequency at which pneumatoceles were observed versus the treatment energy level is summarized in table 2 .

Pneumatoceles were not observed at the lower treatment energy $(125 \mathrm{cal})$. Above $125 \mathrm{cal}$, the incidence of pneumatoceles increased with increasing treatment energy between 270 and $360 \mathrm{cal}$, with up to $79 \%$ of segments treated at $360 \mathrm{cal}$ having evidence of disruption of the lung architecture.

No evidence of adjacent organ damage was observed in animals treated with low energy $(125 \mathrm{cal})$. Of the 9 animals treated with medium to high energy, 4 (44\%) had evidence of damage to the thoracic wall and $4(44 \%)$ had 
Fig. 3. Examples of adjacent tissue effects in the left chest wall (a) and liver (b) of animal 8 .

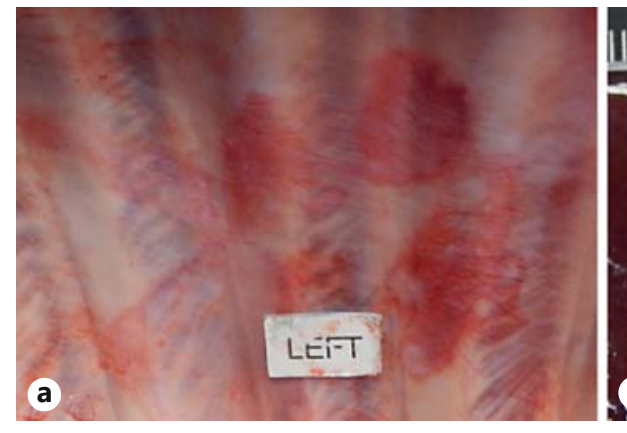

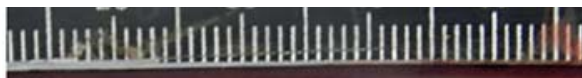

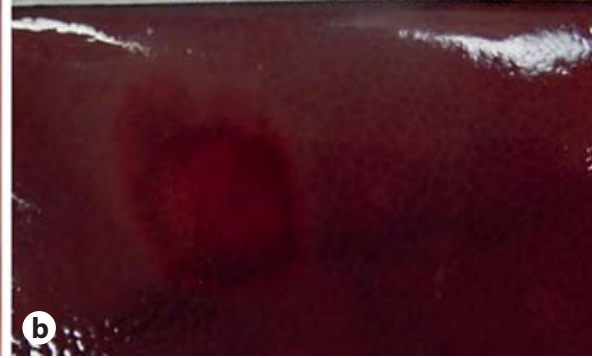

evidence of damage to the liver. All damage observed on both the liver and the thoracic wall was $1 \mathrm{~mm}$ in depth and adjacent to treated regions of the lung. Examples of adjacent tissue effects are shown in figure 3.

Upon necropsy, one of the chronic animals treated with medium power $(270 \mathrm{cal})$, i.e. animal 5 , had a large volume $(600 \mathrm{ml})$ of fluid found in the pericardial sac. The fluid was sampled and a hematocrit of $3 \%$ was measured. No evidence of thermal injury to the pericardial sac or the epicardial heart surface was observed. A smaller volume of fluid was observed in the pericardial sac of animal 6, also treated with 270 cal.

\section{Efficacy}

The primary endpoint for efficacy of the treatment was the presence of uniform necrosis. This was assessed both by gross pathology and by histopathology. Representative gross pathology images of uniform versus nonuniform necrosis after treatment are provided in figure 4 . The number and percentage of treatments at each energy level that were associated with uniform necrosis as determined qualitatively from gross pathology are shown in table 3 .

\section{Histopathology}

A total of 44 lung tissue slides were assessed from 7 animals including all 6 chronic animals and 1 acute animal (No. 11). The primary histopathological finding in the treated lung was necrosis of the alveolar tissue. The alveolar walls in the treated region had a vacuolated appearance, pyknotic nuclei, and an absence of erythrocytes (fig. 5d). Surrounding these regions of necrosis along the anatomical boundary of the subsegment was a ring of alveolar walls that had pyknotic nuclei but also had capillaries distended with erythrocytes (fig. 5c).

In addition to the alveolar damage, other common findings were of damage to airways and arteries. In air-
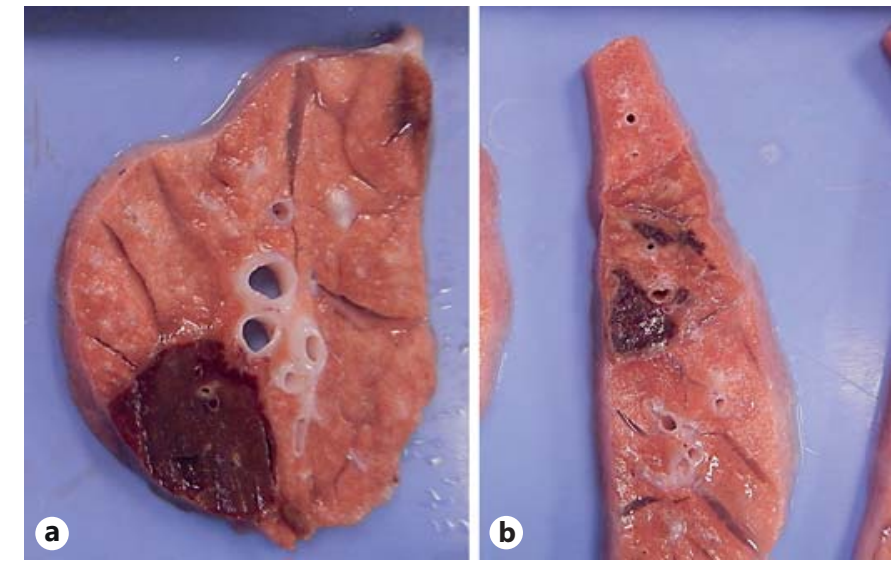

Fig. 4. Representative images of uniform necrosis of a subsegment of LV4 ten days after treatment with $270 \mathrm{cal}$ (animal 3) (a) and nonuniform necrosis of a subsegment of LV6 ten days after treatment with $270 \mathrm{cal}$ (animal 4) (b).

Table 3. Number and percentage of treated segments with uniform necrosis

\begin{tabular}{lll}
\hline Treatment energy & $\begin{array}{l}\text { Treatments, } \\
\mathrm{n}\end{array}$ & $\begin{array}{l}\text { Uniform necrosis } \\
\text { observed, } \mathrm{n}(\%)\end{array}$ \\
\hline $125 \mathrm{cal}$ & 6 & $0(0)$ \\
$270 \mathrm{cal}$ & $27^{\mathrm{a}}$ & $12(44)$ \\
$330 \mathrm{cal}$ & 16 & $14(88)$ \\
$360 \mathrm{cal}$ & 14 & $11(79)$ \\
$390 \mathrm{cal}$ & 12 & $9(75)$ \\
\hline
\end{tabular}

${ }^{\text {a }}$ Unable to assess the 6 treatments in animals with a 32-day survival to a healing effect.

ways, the muscularis mucosa was rarely still present in healing or chronically damaged bronchi (fig. 6b). Some arteries had complete necrosis of their wall, with no healing; their contents were blood debris. Other arteries had 


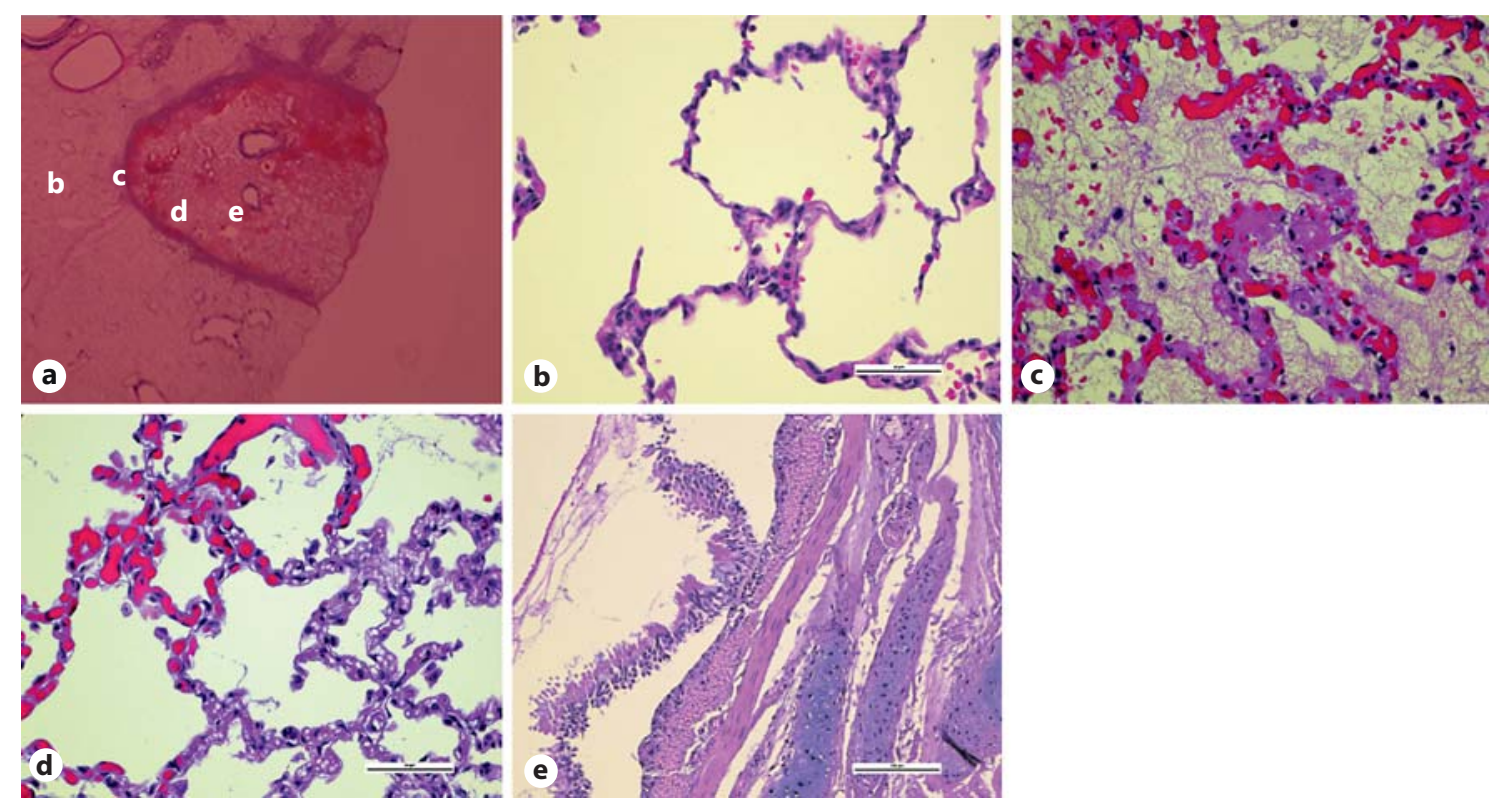

Fig. 5. Ten-day survival. Representative H\&E-stained section of tissue from animal 11. a Treated subsegment of V4 under no magnification showing uniform necrosis following the anatomical boundaries. The letters indicate the corresponding locations of subsequent images. b Normal alveolar walls outside of the affected region. Magnification $\times 40$. c Alveolar walls which are necrotic with erythrocytes. This RBC-rich pattern is characterized by pyknotic nuclei, a lack of cell detail, and distension of capillaries and other small vessels with erythrocytes. This region surrounds the entire affected area. Magnification $\times 40$. d Alveolar walls which are necrotic characterized by a vacuolated appearance, pyknotic nuclei, a lack of cell detail, and an absence of RBC. The edge of the RBCrich pattern is in the upper left. Magnification $\times 40$. e Damage to the bronchial wall. Bronchial epithelium is detached and has a necrotic appearance. Muscularis mucosae is intact. Magnification $\times 20$.

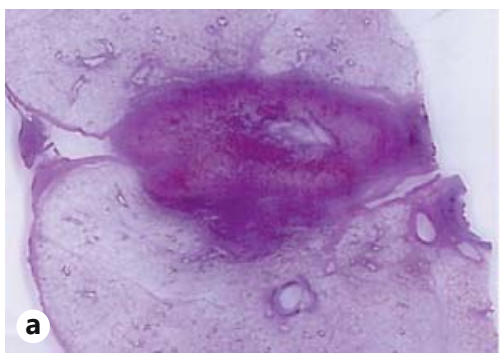

Fig. 6. Thirty-two-day survival. Representative H\&E-stained section of tissue from animal 11. a Three adjacent treated subsegments from segments LD3 and LD2 under no magnification showing one region of uniform necrosis following anatomical boundaries. The ablated region has undergone significant resorption as evidenced by its small size and puckering of the pleura on the left.

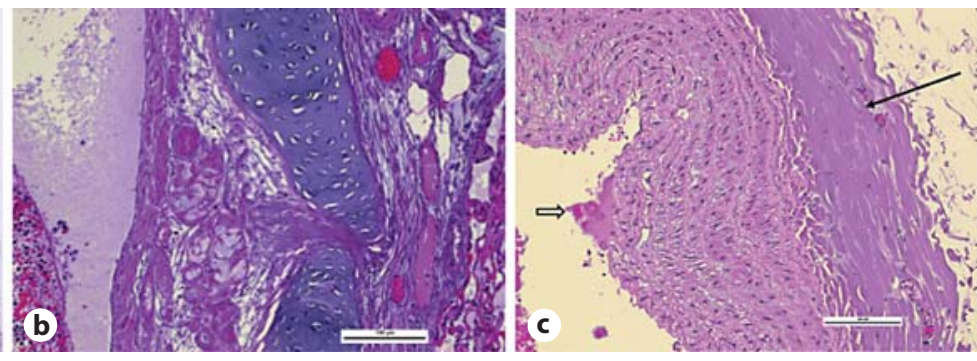

b Damaged bronchial wall with lack of a healing response. The lumen of the bronchus is on the left, with cellular and fluid contents. Magnification $\times 20$. c Acutely injured artery with hyalinized adventitial collagen on the right (closed arrow), an acutely injured arterial wall (next to the hyalinized collagen), and adherence of platelets to the intimal surface (open arrow). Magnification $\times 20$. minimal damage, with only mild intimal proliferation. Other arteries had hyalinization of adventitia but no apparent damage to the arterial wall. Still other arteries contained partly organized thrombi. Hyalinization of adventitial collagen was found in both red blood cell (RBC)-rich areas and areas of altered alveoli (interpreted to be areas of healing sublethal damage). In areas of coagulative necrosis, arteries were almost always necrotic.

In the animals that survived to 32 days, necrotic areas were infiltrated by fibroblasts and essentially became scarred lung tissue. Little actual necrosis remained, and the remaining ablated regions were reduced in size and 
Table 4. Summary of safety findings in chronic animals by energy level

\begin{tabular}{|c|c|c|c|c|c|c|}
\hline \multirow[t]{2}{*}{ Animal No. } & \multicolumn{2}{|l|}{$125 \mathrm{cal}$} & \multicolumn{2}{|l|}{$270 \mathrm{cal}$} & \multicolumn{2}{|l|}{$270 \mathrm{cal}$} \\
\hline & 1 & 2 & 3 & 4 & 5 & 6 \\
\hline Airways treated, n & 3 & 3 & 3 & 3 & 3 & 3 \\
\hline $\begin{array}{l}\text { Additional airways treated (other } \\
\text { methods), } \mathrm{n}\end{array}$ & 2 & 2 & 2 & 2 & none & none \\
\hline Time to euthanasia, days & 21 & 21 & 10 & 10 & 32 & 32 \\
\hline Procedural complications & none & none & none & none & none & none \\
\hline Clinical observations & none & fever & none & $\begin{array}{l}\text { loss of } \\
\text { appetite }\end{array}$ & $\begin{array}{l}\text { fever, loss of } \\
\text { appetite }\end{array}$ & none \\
\hline Clinical pathology & normal & $\uparrow \mathrm{WBC}$ & $\uparrow$ creatine kinase & NCS & $\uparrow \mathrm{WBC}$ & NCS \\
\hline Necropsy findings & none & none & none & none & $\begin{array}{l}\text { pericardial } \\
\text { effusion }\end{array}$ & $\begin{array}{l}\text { mild pericardial } \\
\text { effusion }\end{array}$ \\
\hline Pneumatoceles in treated segments & none & none & 1 of 3 & none & none & none \\
\hline Histopathology & none & infection, inflammation & none & none & none & none \\
\hline
\end{tabular}

$\mathrm{WBC}=$ White blood cells; NCS $=$ not clinically significant.

fibrotic. Aside from the desired necrotic effects, no adverse findings were noted in the lung sections. Thermal fixation was not identified in any of the treated tissues of any animal.

A section of heart tissue from the animal with pericardial effusion (No. 5) was evaluated. The histology finding was of epicardium expanded by fibrosis, plasma cells, and lymphocytes, which extended minimally into the superficial myocardium.

\section{Safety}

An overview of the safety findings in the chronic animals is provided in table 4 .

\section{Discussion}

The study results demonstrate the capability of thermal vapor ablation to create regions of uniform necrosis that follow anatomical subsegment boundaries in normal pig lung tissue. The treatments were shown to be well tolerated in a chronic cohort, with an absence of major adverse events and minimal clinically symptomatic side effects. From a pathological examination, it seems likely that a nodule in the necrotic fields would be destroyed. The lack of perfusion and healing response within the necrotic field suggests that any nodule within that field would subsequently necrose due to ischemia.

Acute tissue injury and necrosis were visually apparent in most of the targeted lung regions in the animals euthanized on the same day as treatment. However, the unifor- mity of the effect (whether the injury was homogeneous or multifocal) did vary. Above $125 \mathrm{cal}$, the uniformity of the necrosis tended to increase with higher energy levels in the range of 270-330 cal, but further improvements in uniformity were not apparent between 330 and $390 \mathrm{cal}$. However, this trend does suggest that the desired treatment effect (uniform necrosis) is related to the amount of energy delivered.

Pneumothorax occurred in 3 of the 5 acutely treated animals, but it was not seen in any of the chronic animals. The pneumothoraces were likely related to the large number of treatments delivered (up to 8 treatments per lung, and 16 per animal) and/or the high energy level (up to 390 cal). Increasing the amount of energy delivered by increasing the treatment energy (and the dependent flow rate) also increased the incidence of undesirable effects such as pneumatoceles (air cavities in the parenchyma). These complications were most frequent at energy levels of $330 \mathrm{cal}$ and above. Pneumatoceles likely occur due to pressure buildup from the high flow rates at the higher energy levels. Pig lungs are unique in that there is no ventilation between sublobar segments, creating a closed space for pressure buildup. Overall, the findings suggest that vapor ablation at $270 \mathrm{cal}$ in a normal porcine lung could cause a uniform field necrosis with a low incidence of pneumatocele formation in the tissue.

The treatments were well tolerated and no major complications were observed in the chronic animals after treatment. Treatment was not associated with any major adverse event or serious clinical sequelae (i.e. embolism, infarct, respiratory failure, or pneumothorax). 
There were limitations in this study. Because the mechanism of vapor ablation is to induce a field of necrosis in the parenchymal tissue around a lesion, evaluation of the technique in normal tissue gives a reasonable indication of the response and capability of the technique. However, the response of a viable lesion in the field of necrosis generated by vapor ablation cannot be evaluated based on preclinical studies. Currently there are no reasonable large-animal lung tumor models, which is a limitation of all preclinical tumor ablation studies [13]. While the pig lung has many anatomical similarities with the human lung, one major difference is the absence of collateral ventilation between subsegmental regions in the pig lung. Theoretically, this lack of collateral ventilation in the pig lung creates a closed path that restricts vapor flow to adjacent subsegments. This may have two consequences: a reduction in the uniformity of treatment and an increase in pressure within the closed system that may contribute to pneumatocele formation. Thus, a similar energy of $270 \mathrm{cal}$ in the human lung may have improved efficacy (due to collateral ventilation improving the uniformity of the treatment effect) and improved safety (due to collateral ventilation minimizing pressure in the treated area).

An additional limitation is the large number of treatments delivered to each lung. To minimize the total number of animals used, as many treatments as possible were performed in the acute animals and vapor treatments of other methods were performed in the other lung of some of the chronic animals. It was not possible to discern whether the clinical effects observed were attributable to the high number of treatments, the other methods tested, or the treatment being studied.

\section{Conclusion}

The results of this study in live pig tissue suggest that vapor ablation for lung lesions has the potential to create a field of necrosis, which would result in efficient destruction of any lesions within it due to secondary ischemia. In the pig model, an energy level of $270 \mathrm{cal}$ reliably created uniform necrosis with a low rate of pneumatocele formation. In human tissue, where intralobar collateral ventilation is present, it is possible that a higher energy level may be successfully used.

Vapor ablation has the potential to provide an effective local control therapy for primary and secondary lung tumors in a fast and low-cost manner. The bronchoscopic approach of energy delivery through the natural tissue lumens could have a significantly lower patient impact compared to surgery, SBRT, or percutaneous approaches. Vapor ablation for lung lesions should be investigated further in human tissue.

\section{Acknowledgements}

This study was funded entirely by Uptake Medical. The authors would like to acknowledge Dr. James Coad of West Virginia University and Dr. Rebecca Rose for their histopathology analysis and Dr. Stephanie Tuck for her assistance with study reporting.

\section{References}

1 Thanos L, Mylona S, Pomoni M, Athanassiadi K, Theakos N, Zoganas L, Batakis N: Percutaneous radiofrequency thermal ablation of primary and metastatic lung tumors. Eur J Cardiothorac Surg 2006;30:797-800.

2 Haasbeek CJa, Senan S, Smit EF, Paul MA, Slotman BJ, Lagerwaard FJ: Critical review of nonsurgical treatment options for stage I non-small cell lung cancer. Oncologist 2008; 13:309-319.

3 Tanvetyanon T, Finley DJ, Fabian T, Riquet M, Voltolini L, Kocaturk C, Fulp WJ, Cerfolio RJ, Park BJ, Robinson LA: Prognostic factors for survival after complete resections of synchronous lung cancers in multiple lobes: pooled analysis based on individual patient data. Ann Oncol 2013;24:889-894

4 Vogl TJ, Naguib NN, Lehnert T, Nour-Eldin NE: Radiofrequency, microwave and laser ab- lation of pulmonary neoplasms: clinical studies and technical considerations - review article. Eur J Radiol 2011;77:346-357.

5 Yamauchi Y, Izumi Y, Kawamura M, Nakatsuka $S$, Yashiro $H$, Tsukada $N$, Inoue $M$, Asakura K, Nomori H: Percutaneous cryoablation of pulmonary metastases from colorectal cancer. PLoS One 2011;6:e27086.

6 Moreno B, Nemcek AA: Pulmonary radiofrequency ablation complicated by tension pneumothorax. Semin Intervent Radiol 2011; 1:183-186.

7 Yoshimatsu R, Yamagami T, Terayama K, Matsumoto T, Miura H, Nishimura T: Delayed and recurrent pneumothorax after radiofrequency ablation of lung tumors. Chest 2009;135:1002-1009.

8 Timmerman RD, Herman J, Cho LC: Emergence of stereotactic body radiation therapy and its impact on current and future clinical practice. J Clin Oncol 2014;32:2014.

9 Eberhardt R, Kahn N, Herth FJF: 'Heat and destroy': bronchoscopic-guided therapy of peripheral lung lesions. Respiration 2010;79: 265-273.

10 Snell GI, Hopkins P, Westall G, Holsworth L, Carle A, Williams TJ: A feasibility and safety study of bronchoscopic thermal vapor ablation: a novel emphysema therapy. Ann Thorac Surg 2009;88:1993-1998.

11 Herth FJF, Ernst A, Baker KM, Egan JJ, Gotfried MH, Hopkins P, Stanzel F, Valipour A, Wagner M, Witt C, Kesten S, Snell G: Characterization of outcomes 1 year after endoscopic thermal vapor ablation for patients with heterogeneous emphysema. Int I Chron Obstruct Pulmon Dis 2012;7:397405. 
12 Dupuy DE: Science to practice: microwave ablation compared with radiofrequency ablation in lung tissue - is microwave not just for popcorn anymore? Radiology 2009;251:617618.

13 Durick N, Laeseke P, Broderick L, Lee FT, Sampson LA, Frey TM, Warner TF, Fine JP, van der Weide DW, Brace CL: Microwave ablation with triaxial antennas tuned for lung: results in an in vivo porcine model. Radiology 2008;247:80-87.
14 Yamamoto A, Nakamura K, Matsuoka T, Toyoshima M, Okuma T, Oyama Y, Ikura Y, Ueda M, Inoue Y: Radiofrequency ablation in a porcine lung model: correlation between CT and histopathologic findings. AJR Am J Roentgenol 2005;185:1299-1306.

15 Nomori H, Imazu Y, Watanabe K, Ohtsuka T, Naruke T, Kobayashi T, Suemasu K: Radiofrequency ablation of pulmonary tumors and normal lung tissue in swine and rabbits. Chest 2005; 127:973-977.

16 Raman SS, Lu DSK, Vodopich DJ, Sayre J, Lassman C: Creation of radiofrequency lesions in a porcine model: correlation with sonography, CT, and histopathology. Am J Roentgenol 2000;175:1253-1258.
17 Lesser TG, Ritter F, Schlosser H, Boltze C, Hackenbroich C: Effects of radiofrequency ablation on normal lung tissue in a swine model. Acad Radiol 2011;18:1318-1323.

18 Henne E, Anderson JC, Barry R, Kesten S: Thermal effect of endoscopic thermal vapour ablation on the lung surface in human ex vivo tissue. Int J Hyperthermia 2012;28:466-472.

19 Nakakuki S: Bronchial tree, lobular division and blood vessels of the pig lung. J Vet Med Sci 1994;56:685-689. 